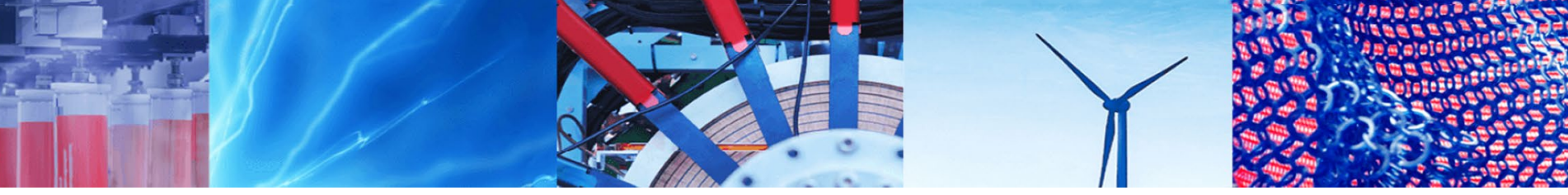

Research Article

\title{
Cutting inserts made of glass and glass ceramics
}

\author{
Bernd Breidenstein ${ }^{1}$ (D) Dominik Müller-Cramm ${ }^{1}$ (I) $\cdot$ Nils Vogel $^{1}$ (I)
}

Received: 29 July 2021 / Accepted: 19 November 2021

Published online: 29 November 2021

(c) The Author(s) 2021 OPEN

\begin{abstract}
Against the background of the increasing cost and scarcity of raw materials that are required for the manufacture of cutting tools, the question of alternative cutting materials arises. Glasses and glass ceramics represent a possibility for this, the use of which has hardly been considered so far. This thesis is devoted to the question of whether cutting tools can be made from glass and glass ceramic materials at all. In addition, the question of how such tools can be used for which purposes is dealt with. First results on both questions are presented. The grinding of indexable inserts from the materials examined was possible without breaking corners and edges. Plastics can be easily machined with the tools produced. When machining aluminum, however, the tools made of glass fail completely, while those made of glass-ceramic show good results here too. These first results are intended to pave the way for further research in this area.
\end{abstract}

\section{Article Highlights}

- The study shows that it is possible to manufacture tools from glass and glass-ceramic for machining by grinding.

- Glass tools are suitable for machining plastic, glass ceramic tools can be used for machining plastic and aluminum.

- Glass ceramic tools could represent an alternative to common tool materials. More research is needed.

Keywords Grinding · Glass and glass ceramic · Cutting tools · Plastics · Aluminum

\section{Introduction}

Grinding is one of the most important machining methods in the manufacture of components for a wide variety of applications. Grinding processes are therefore one of the most frequently examined processes, and not all relationships between the process control variables and their effects on the component properties have been understood yet. From the huge and still increasing number of scientific publications, only a few from the last about twenty years are cited here as examples.
Not all of the large number of abrasive grains that are on the surface of a grinding wheel come into contact with the workpiece. Rather, the number of grains that actually remove material from the workpiece surface is very small. Many of the grains only have plowing or rubbing contact with the workpiece [1]. With the help of newly developed quick-stop methods, it is possible to better understand the material removal processes using chip root examinations. The number of active grains correlates well with the Abbot curve of the grinding wheel surface. The type of chip formation can be further differentiated

Bernd Breidenstein, breidenstein@ifw.uni-hannover.de | 'Institute of Production Engineering and Machine Tools, Leibniz University Hannover, Hannover, Germany.

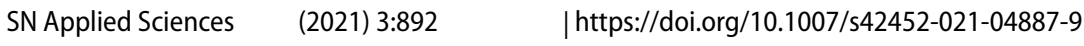


by these investigations. Larger grains are responsible for the formation of chips, while smaller ones tend to cause micro-plowing effects [2]. With the help of a quick-stop device, the material separation mechanisms could also be analyzed when grinding ceramic material. A resin-bonded grinding wheel shows rather ductile cutting mechanisms, as it has a large number of active abrasive grains in the contact zone [3].

The question of the generation of residual stresses in the component as a result of grinding is a very complex issue. Residual stresses arise from the superposition of thermal and mechanical loads on the component during processing and the subsequent cooling. The residual stresses present in the component before grinding largely determine the final residual stress state of the component. Residual stresses in geometrically complex components have not yet been investigated in detail. The wear condition of the grinding tool is of great importance for the surface and subsurface quality of the component, which is why an automatic process-integrated monitoring and dressing of the grinding wheel was developed [4]. Since the thermal load on the workpiece during grinding is also responsible for the development of residual stresses, the determination of contact temperatures is of great importance. The basic principles of heat transfer are quite well understood, but the use of cooling lubricants complicates the consideration of the thermal load component [5].

Due to the great complexity of the questions, efforts have been made for a long time to model and simulate grinding processes in order to adapt them to the requirements as optimally as possible. Different models have been developed for the purpose of modeling and simulating grinding processes. They can be divided into analytical and numerical models, empirical process models and heuristic process models. On the one hand, they take into account process parameters (grinding force, grinding temperature) and, on the other hand, work results (surface topography, subsurface properties) [6]. Most publications on the subject of grinding relate to metallic materials. But the grinding of other groups of materials is also dealt with in the literature, e.g., ceramics, wood, stones or glass $[7,8]$.

Current studies are concerned with ways of finding alternative materials for cutting tools with a geometrically defined cutting edge, as the raw materials used for this (such as $\mathrm{Co}$ and $\mathrm{W}$ for carbides) are increasingly difficult to obtain on the world market. An example of this are the attempts to grind cutting tools made of naturally occurring rocks and use them for machining, for example aluminum and plastics [9]. This led to the question of whether it is basically possible to grind cutting tools from glass and glass ceramics, which can then be used to machine plastics and aluminum. The results of the first investigations are presented.

\section{Materials and methods}

\subsection{Materials}

Since there is no experience in the field of grinding glass and glass ceramics into cutting tools, two glass materials and one glass ceramic are arbitrarily selected as test materials: one glass is a soda-lime-silica glass, the second one is a lead glass. The glass ceramic Vitronit ${ }^{\oplus}$ is a white, pore-free and non-outgassing mica glass ceramic for technical applications from the company Vitron, Jena, Germany. This material has been chosen as according to the manufacturer's information it can be finished by turning and milling operations and should therefore also be suitable for grinding. In this context, glass ceramics are a very interesting group of materials because some of them have very low, sometimes even negative coefficients of thermal expansion. The probability of thermally induced cracking can therefore be significantly reduced. The Vitronit glass ceramic does not have a low coefficient of thermal expansion. It consists of $\mathrm{SiO}_{2}, \mathrm{Al}_{2} \mathrm{O}_{3}, \mathrm{MgO}, \mathrm{K}_{2} \mathrm{O}, \mathrm{Na}_{2} \mathrm{O}$ and $\mathrm{F}$. Its mica crystalline phase is about $60 \%$, the glass matrix about $40 \%$. Energy dispersive X-ray analyses of the three materials delivered the distribution of chemical elements as represented in Table 1.

Hardness of the three tool materials as well as that of the three materials to be machined was determined according to Vickers HV0.5 on a Struers Duramin hardness tester. This method was chosen in order to check at a very early stage whether the selected tool materials are decisively harder than the materials to be machined, and

Table 1 Chemical composition of the materials (in wt.-\%)

\begin{tabular}{llll}
\hline Element & Vitronit $^{\oplus}$ & $\begin{array}{l}\text { Soda-lime-silica } \\
\text { glass }\end{array}$ & Lead glass \\
\hline $\mathrm{C}$ & 10.44 & 0.37 & 1.92 \\
$\mathrm{O}$ & 42.38 & 40.69 & 26.34 \\
$\mathrm{~F}$ & 3.35 & 0.16 & 0.48 \\
$\mathrm{Na}$ & 3.48 & 9.35 & 1.33 \\
$\mathrm{Mg}$ & 6.14 & 2.26 & 0.10 \\
$\mathrm{Al}$ & 12.77 & 0.59 & 2.05 \\
$\mathrm{Si}$ & 17.40 & 38.31 & 14.85 \\
$\mathrm{~K}$ & 3.08 & 0.07 & 1.57 \\
$\mathrm{Ca}$ & 0.66 & 6.37 & - \\
$\mathrm{Pb}$ & - & - & 51.03 \\
$\mathrm{Fe}$ & 0.14 & 0.07 & 0.19 \\
$\mathrm{Ni}$ & - & - & 0.14 \\
$\mathrm{Cl}$ & 0.16 & - & - \\
$\mathrm{Sn}$ & - & 1.76 & - \\
$\mathrm{Total}$ & 100.00 & 100.00 & 100.00 \\
\hline
\end{tabular}


therefore come into question as cutting tools at all. In addition, it was necessary to determine the hardness of the materials available to us individually, since Garai et al. have shown, using the example of $\mathrm{Ag} / \mathrm{Au}$-doped glass ceramics, that the hardness depends on the composition [10]. They also showed that the higher the hardness of glass-ceramics, the lower their machinability [11]. The three cutting materials to be examined here cover a hardness range from $220 \pm 36$ (Vitronit) to $537 \pm 7$ HV0.5 (soda-lime-silica glass) (Fig. 1, left). The hardness values of the materials to be machined will be discussed later.

Blanks of the size $13 \mathrm{~mm} \times 13 \mathrm{~mm}$ were prepared by abrasive cutting, the thickness of the blanks was $t=4 \mathrm{~mm}$ for soda-lime-silica glass and Vitronit, and $\mathrm{t}=5 \mathrm{~mm}$ for the lead glass.

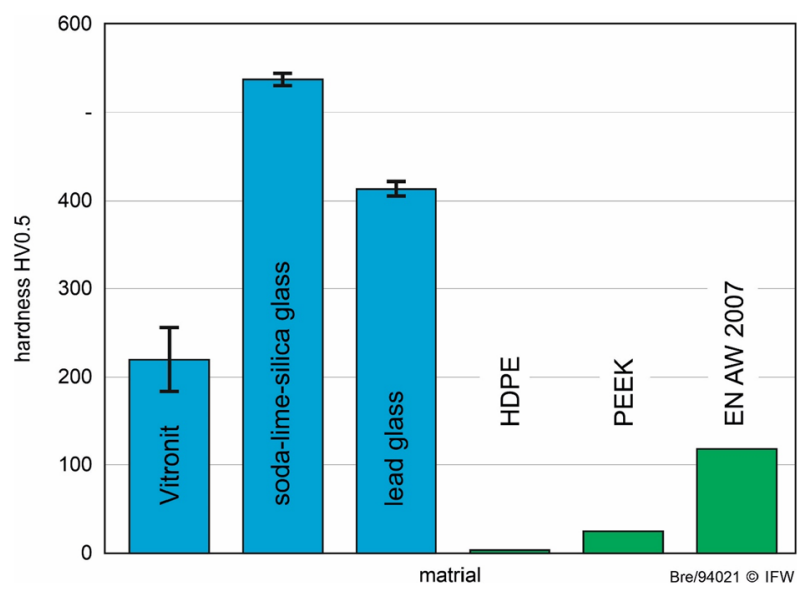

Fig. 1 Hardness HV 0.5 of the investigated materials

\subsection{Grinding}

The blanks were ground on a face grinding machine tool type Wendt WAC 715 Centro, using a diamond cup grinding wheel D10 $\mathrm{c} 100$ with open-pored vitrified bond and a wheel diameter of $d=400 \mathrm{~mm}$. Cutting speed was $v_{c}=15 \mathrm{~m} / \mathrm{s}$ for glass and Vitronit 1 , and $v_{c}=20 \mathrm{~m} / \mathrm{s}$ for Vitronit 2 . Feed velocity in axial direction was $v_{f a}=1 \mathrm{~mm} / \mathrm{min}$. A mineral oil was used as a cooling lubricant (Fig. 2). The final size of the glass tools was $12.5 \times 12.5 \times 4 \mathrm{~mm}^{3}$, and $12.5 \times 12.5 \times 5 \mathrm{~mm}^{3}$, respectively (Fig. 5).

A second set of Vitronit tools was prepared with special attention to the cutting corners. On the one hand tools with as sharp as possible and on the other hand tools with clearly rounded cutting corners should be produced.

\subsection{Tool characterization}

After grinding different tool properties have been determined at different positions of the inserts (Fig. 3). On the flank face (1) the roughness values $R a, R z$ and $R$ max have been determined using a tactile roughness measuring system type MarSurf LD 130 from Mahr Group, Germany. Corner (2) and edge roundings (3) and (4) have been measured using an optical topography measuring device TOOLinspect from Confovis GmbH, Germany.

Vickers hardness values HV0.5 (see Fig. 1) were obtained using a hardness tester type Duramin from Struers, Germany. The chemical composition of the glass and glass ceramic material (see Table 1) was determined using an energy dispersive X-ray equipment-type EDAX Octane Elite from Ametek, USA. Tool details were examined and
Fig. 2 Grinding of cutting inserts from glass ceramics
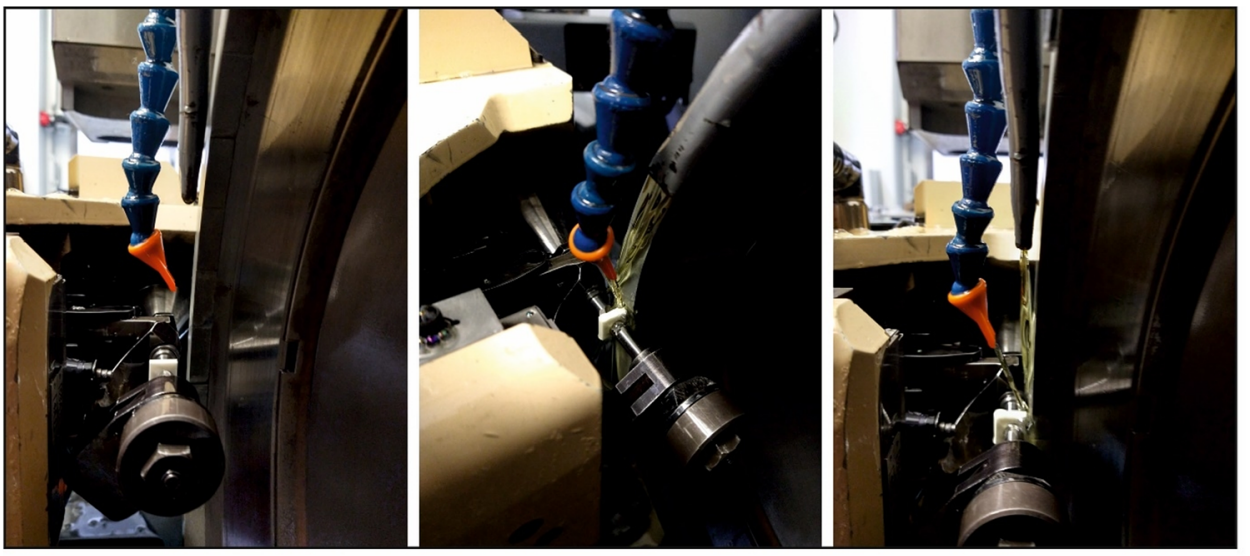

grinding tool

diamond D10 c100

open-pored vitrified bond diameter: $400 \mathrm{~mm}$ process parameters

$\mathrm{v}_{\mathrm{C}}=15 \mathrm{~m} / \mathrm{s}$ and $20 \mathrm{~m} / \mathrm{s}$

$\mathrm{v}_{\mathrm{fa}}=1 \mathrm{~mm} / \mathrm{min}$

coolant: mineral oil

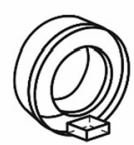

Bre/94022 @ IFW 


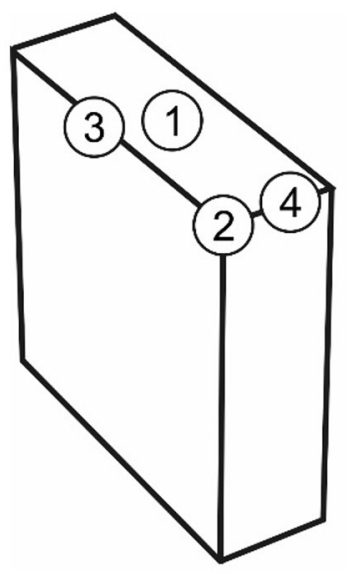

\section{(1) roughness \\ (2) corner rounding \\ (3) edge rounding \\ (4) edge rounding}

Fig. 3 Measuring positions for characterization

documented using a scanning electron microscope-type EVO 60 VP by Zeiss, Germany.

\subsection{Turning}

In order to test to what extent the manufactured inserts can be used in machining at all, turning tests were carried out on the plastics HDPE (high-density polyethylene) and PEEK (polyetheretherketone) as well as on the aluminum alloy EN AW 2007. All experiments were carried out on a lathe CTX 520 L by Gildemeister, Germany, using the settings shown in Table 2.

For the machining of HDPE and aluminum a combined turning process was applied: In the first step a grooving with the tool orientation as shown in Fig. 4 was performed followed by a retraction of the tool to half the cutting depth and then cylindrical turning. A second turning process, applied to PEEK and aluminum, consists of classical cylindrical turning with the cutting corner.

\section{Results}

\subsection{Grinding}

Cutting inserts could be ground successfully from all three materials (Fig. 5). At first glance the edges and corners of the tools look flawless and evenly sharp. SEM images of the edges confirm this finding and show edges without major breakouts or defects (Fig. 6). The edge roundings $r_{b}$ were determined at the positions 3 and 4 from Fig. 3 and show comparable values except for edge \#4 from the soda-lime-silica glass, which is not quite as sharp as the other edges (Table 3).
Table 2 Process parameters for the turning experiments

\begin{tabular}{llll}
\hline Parameter & Grooving & Cylindrical turning & Cylindrical turning \\
\hline Material & HDPE & HDPE & PEEK, aluminum EN AW 2007 \\
Tool material & glass, Vitronit & glass, Vitronit & Vitronit \\
Cutting speed $\mathrm{v}_{\mathrm{c}}$ & $70 \mathrm{~m} / \mathrm{min}$ & $70 \mathrm{~m} / \mathrm{min}$ & $200 \mathrm{~m} / \mathrm{min}$ \\
Feed $\mathrm{f}$ & $0.05 \mathrm{~mm}$ & $0.05 \mathrm{~mm}$ & $0.1 \mathrm{~mm}$ \\
Depth of cut $\mathrm{a}_{\mathrm{p}}$ & & $0.5 \mathrm{~mm}$ & $0.2 \mathrm{~mm}$ (PEEK); 0.1 mm (aluminum) \\
Corner radius $\mathrm{r}_{\mathrm{e}}$ & & & $\sim 10 \mu \mathrm{m} ; 400 \mu \mathrm{m}$ \\
Path length due to & & & $\sim 3,500 \mathrm{~m}$ (PEEK); $310 \mathrm{~m}$ (aluminum) \\
primary motion $\mathrm{I}_{\mathrm{c}}$ & & & \\
\hline
\end{tabular}

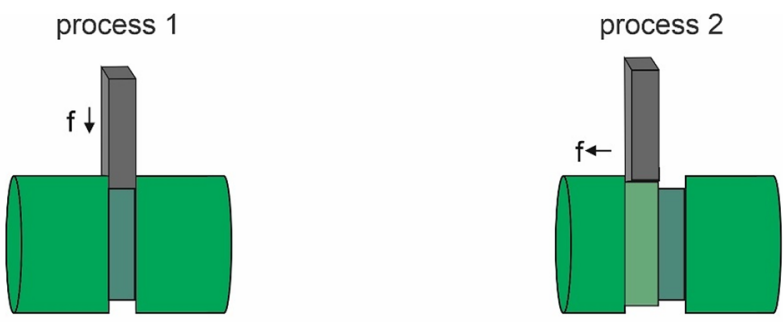

$\begin{array}{ll}\text { process 2: } & \text { material: } \\ \text { cylindrical turning } & \text { HDPE (high density } \\ v_{c}=70 \mathrm{~m} / \mathrm{min} & \text { polyethylene) } \\ f=0,05 \mathrm{~mm} & d=58 \mathrm{~mm} \\ a_{p}=0,5 \mathrm{~mm} & \mathrm{l}=310 \mathrm{~mm}\end{array}$

tool material:

glass and

glass ceramic

Bre/94029 ㄷ IFW 


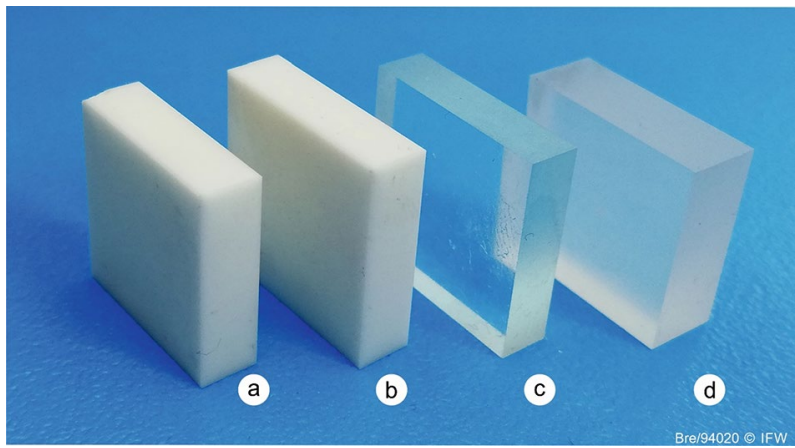

Fig. 5 Ground cutting inserts from Vitronit $(a, b)$, soda-lime-silica glass (c) and lead glass (d)

All cutting corners of the tools of the first series also show extremely cleanly manufactured conditions without any abnormalities in the SEM images (Fig. 7). The tools of the second series were made exclusively from Vitronit. On the one hand, they should have very sharp corners and, on the other hand, a targeted, larger corner rounding should be set. The SEM images of the cutting corners in Fig. 8 show that this was successful. The roughness values, measured on the flank face, are in a typical size range for the grinding process used with $\mathrm{Ra} \leq 1 \mu \mathrm{m}, \mathrm{Rz}=6-8 \mu \mathrm{m}$ and Rmax $=7-9 \mu \mathrm{m}$ (Fig. 9).

Cutting inserts from two types of glass and one glass ceramic could be ground successfully. Corners, edges and surface roughness are not objectionable. To assess whether these tools can actually be used for machining, different turning tests were carried out on two plastics and an aluminum alloy.

\subsection{Combined turning process}

The three materials HDPE, PEEK and aluminum EN AW 2007 were selected because they are less hard than the cutting materials (see Fig. 1), a prerequisite for using the tools. The hardness specifications for these materials vary somewhat as they depend on their composition and heat treatment. For the consideration in this work, mean values were taken from the literature: for HDPE from [12], for PEEK from [13] and for EN AW 2007 from [14]. What they all have in common is that they are significantly less hard than the cutting materials (Fig. 1). The combined turning process (see Fig. 4) on HDPE could be carried out without any problems (Fig. 10, left). The roughness values in the HDPE, measured in the cylindrical turning part, show comparable values which indicate an undisturbed process sequence. The use of lead glass leads to slightly higher roughness values than the other two cutting materials (Fig. 11). The reason for the higher roughness values when using lead glass has not yet been clarified. At the current state of knowledge, it can be assumed that different properties of the tool materials (thermal conductivity, coefficient of friction) lead to different mechanical and thermal loads on the component material during machining, resulting

Table 3 Edge rounding $r_{b}$ after grinding (in $\mu \mathrm{m}$ ), (mean from 200 measurements)

\begin{tabular}{lllll}
\hline Edge & Vitronit $^{\oplus 1}$ & Vitronit $^{\oplus} 2$ & $\begin{array}{l}\text { Soda-lime- } \\
\text { silica glass }\end{array}$ & Lead glass \\
\hline$\# 3$ & $15.3 \pm 0.05$ & $26.7 \pm 0.1$ & $14.7 \pm 0.2$ & $25.6 \pm 0.1$ \\
$\# 4$ & $14.8 \pm 0.09$ & $13.4 \pm 0.08$ & $42.3 \pm 0.2$ & $14.4 \pm 0.1$ \\
\hline
\end{tabular}

Fig. 6 SEM photographs of cutting edges of the ground tools

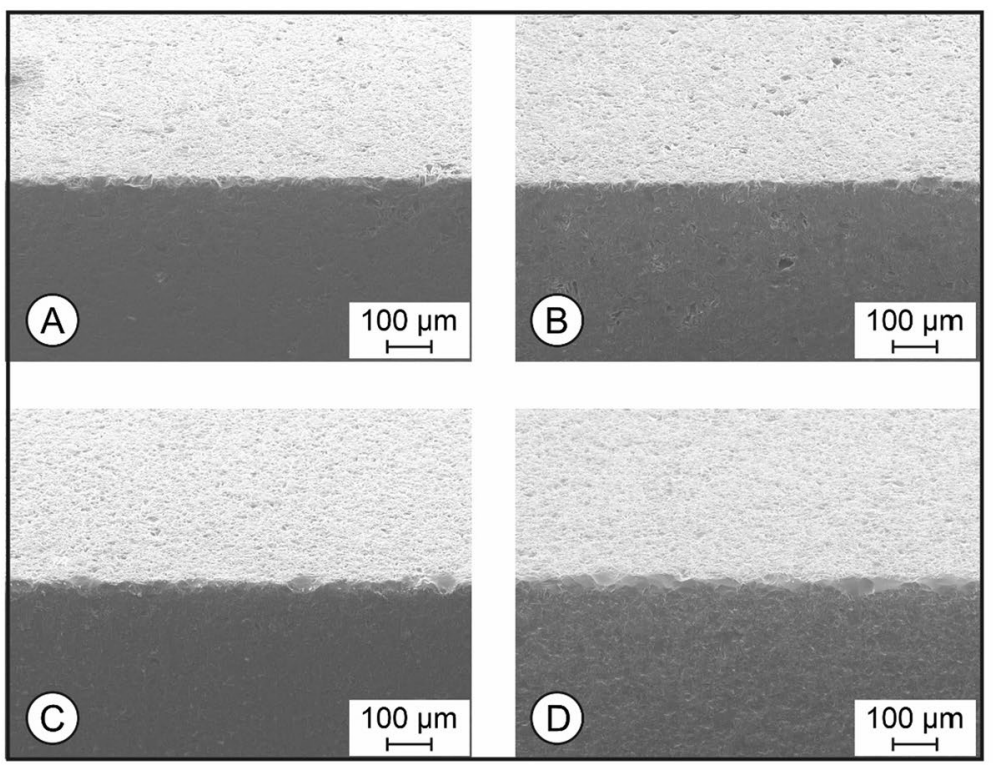

A: Vitronit 1

B: Vitronit 2

C: Soda-limesilica glass

D: Lead glass

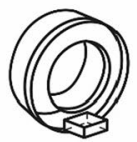

Bre/94025 @ IFW 
Fig. 7 SEM photographs of cutting corners of the ground tools

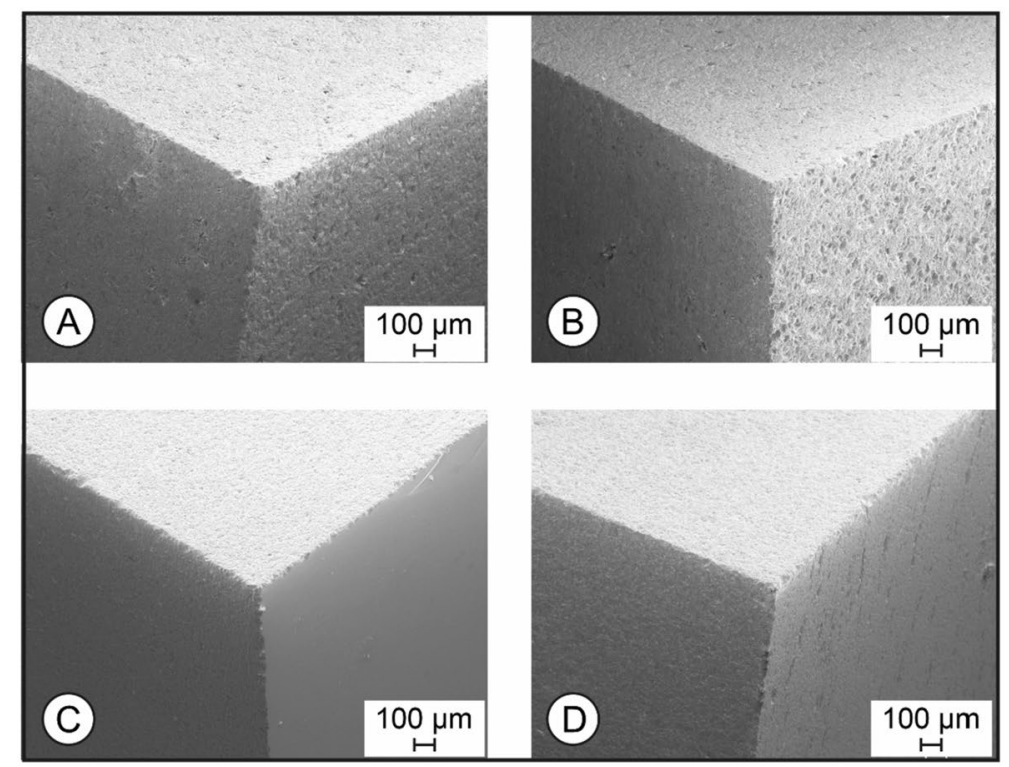

A: Vitronit 1

B: Vitronit 2

C: Soda-limesilica glass

D: Lead glass

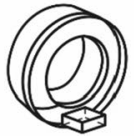

Bre/94024 ㄷ IFW
Fig. 8 SEM photographs of cutting corners of the Vitronit tools, $\operatorname{sharp}(\mathbf{A})$ and rounded $(\mathbf{B})$

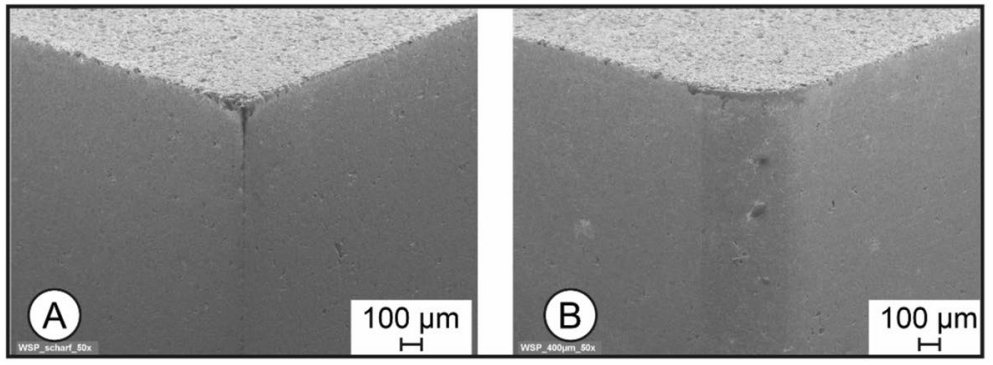

A: corner radius $r_{\varepsilon}=8 \mu \mathrm{m}$

B: corner radius $r_{\varepsilon}=378 \mu \mathrm{m}$

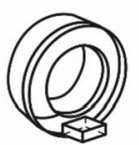

Bre/94031 @ IFW

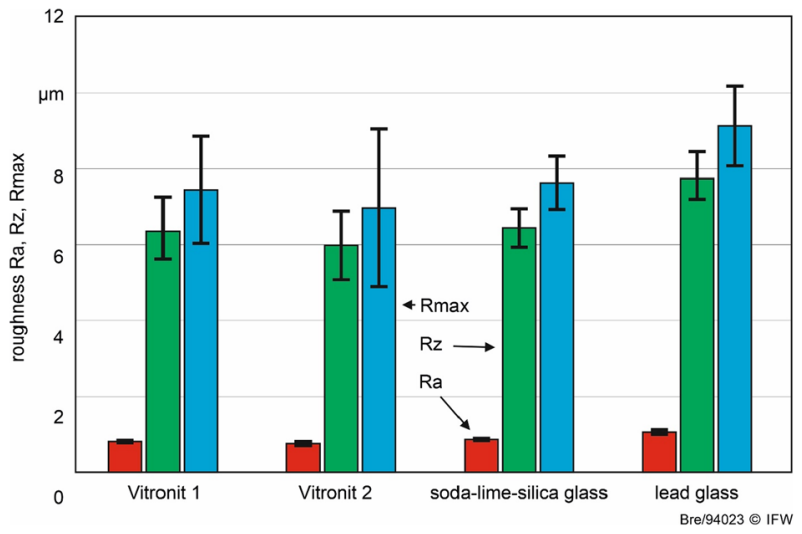

Fig. 9 Surface roughness on the flank face of the ground tools

in different surface roughness. It should also be taken into account that the lead glass tools already have a somewhat greater roughness after grinding. This in turn is due to the different fracture toughness KIC, Young's modulus and hardness of the tool materials [15]. The Vitronit tools can also be used for the machining of aluminum, while the soda-lime-silica glass bursts into many small individual pieces after a short time while grooving (Fig. 10, right). The lead glass shattered at the first contact with the aluminum. For this reason, only the Vitronit tools were used for the further turning tests. The two types of glass apparently have such strong internal stresses that they exceed a critical load limit when external loads occur. In this state, the glasses examined here are not suitable as cutting tool material for the aluminum alloy.

\subsection{Cylindrical turning}

Uncoated cemented carbide inserts [16] or even polycrystalline diamond inserts $[17,18]$ have so far been used for the cylindrical turning of PEEK material. The order of magnitude of the process control variables used in this work is based on the three publications.

The turning operation with the control variables specified in Table 2 could be carried out without any problems. After machining, the surface of the PEEK material showed comparable roughness values when using tools with rounded and 
Fig. 10 Results of the combined turning process of different materials with different tool materials material 1 (HDPE)

material 2 (EN AW 2007)

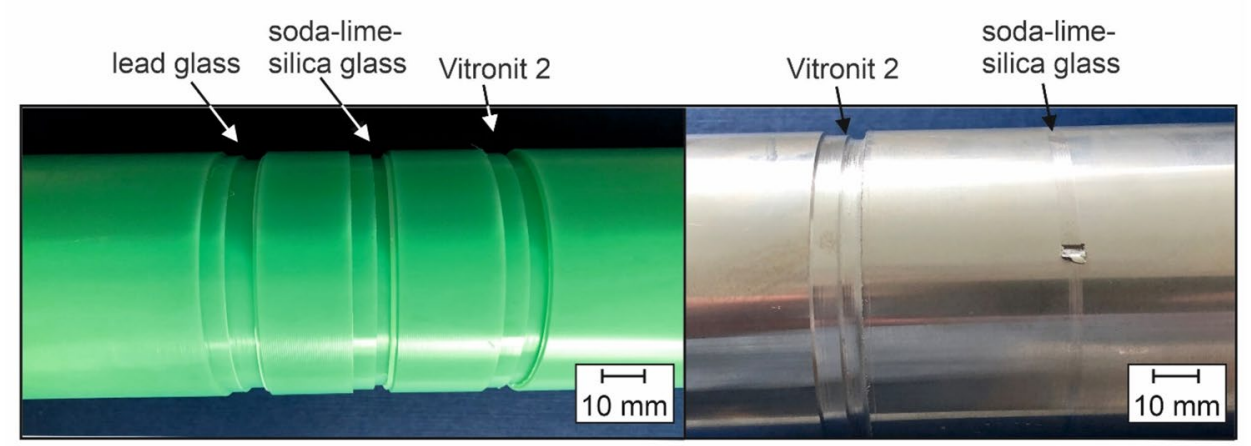

\begin{tabular}{|c|c|c|c|c|}
\hline $\begin{array}{l}\text { process 1: } \\
\text { grooving }\end{array}$ & $\begin{array}{l}\text { process 2: } \\
\text { cylindrical turnin }\end{array}$ & $\begin{array}{l}\text { material 1: } \\
\text { HDPE (high density }\end{array}$ & $\begin{array}{l}\text { material 2: } \\
\text { aluminum }\end{array}$ & $\begin{array}{l}\text { tool material: } \\
\text { glass and }\end{array}$ \\
\hline$c=70 \mathrm{~m} / \mathrm{min}$ & $\mathrm{v}_{\mathrm{c}}=70 \mathrm{~m} / \mathrm{min}$ & polyethylene) & EN AW 2007 & glass ceramic \\
\hline$=0,05 \mathrm{~mm}$ & $f=0,05 \mathrm{~mm}$ & $\mathrm{~d}=58 \mathrm{~mm}$ & $\mathrm{~d}=66 \mathrm{~mm}$ & \\
\hline groove depth $=1 \mathrm{~mm}$ & $a_{p}=0,5 \mathrm{~mm}$ & $\mathrm{I}=310 \mathrm{~mm}$ & $\mathrm{I}=200 \mathrm{~mm}$ & $\mathrm{Bre} / \mathrm{s}$ \\
\hline
\end{tabular}

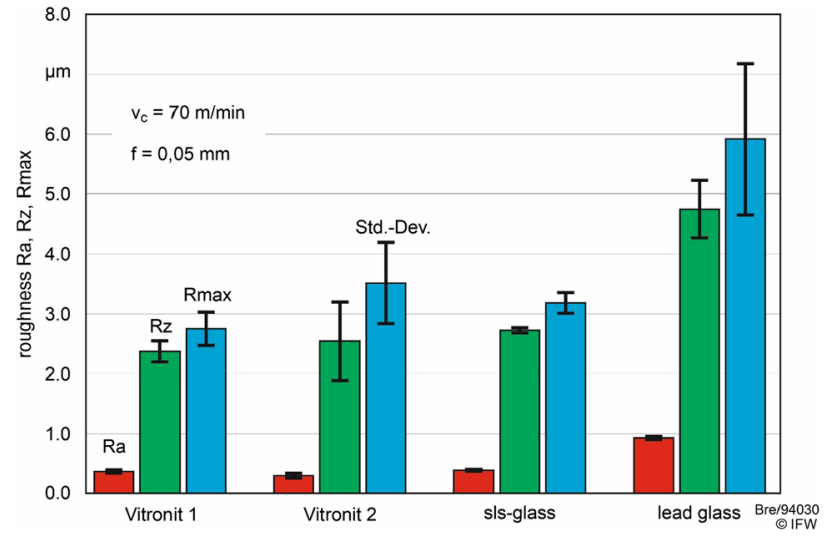

Fig. 11 Surface roughness of HDPE after cylindrical turning

sharp corners. The surface of the aluminum had even better roughness values when using the sharp corner (Fig. 12).

The condition of the cutting corners after use in PEEK (cutting path 3,500 m) and in aluminum (cutting path $310 \mathrm{~m}$ ) was documented by scanning electron microscope images (Fig. 13). During PEEK processing, one sees adhering, apparently previously melted, plastic material on the cutting corners (rounded and sharp) (Fig. 13, top). Due to the aluminum machining, the rounded cutting corner has broken away. On the sharp cutting corner machining, the aluminum has accumulated material. As a result, the state of the corner itself cannot be recognized (Fig. 13, bottom).

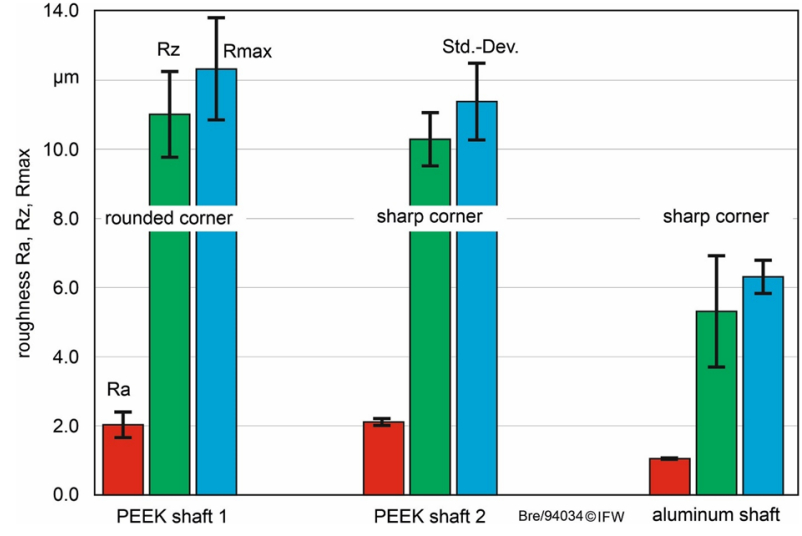

Fig. 12 Surface roughness of PEEK and aluminum after cylindrical turning

\section{Conclusions and outlook}

Grinding as a universal machining process for producing high-quality surfaces is used for a wide variety of materials, including the machining of glass. From the point of view of increasingly expensive and scarce raw materials for the production of classic cutting tool materials, the question was dealt with here as to whether it is possible with the available processing methods to grind simple cutting tools from arbitrarily selected glass or glass ceramic materials.

- The grinding of tools with the manipulated variables used here turned out to be problem-free. The tools could be manufactured in the desired macro- and micro-geometry. 
Fig. 13 SEM photographs of corners of the Vitronit tools after cylindrical turning of PEEK and aluminum

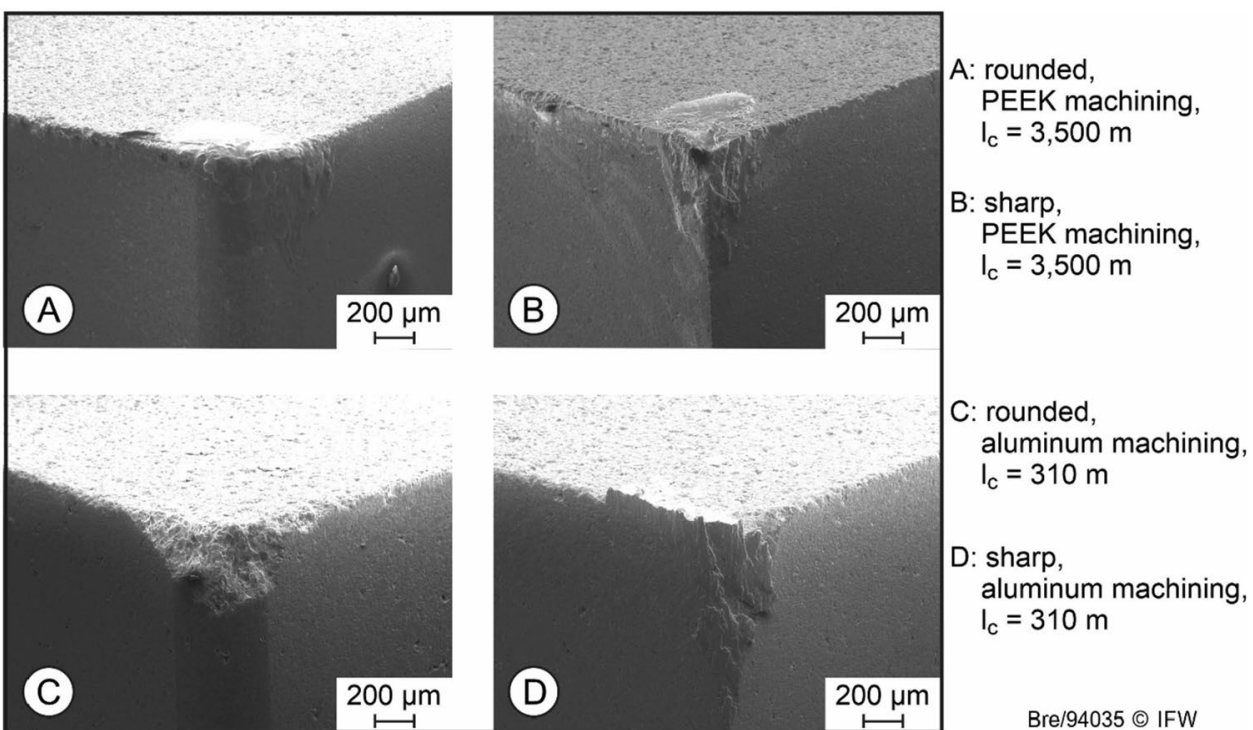

- The question of a possible use of these tools was investigated on the basis of machining tests on two plastics and an aluminum alloy. All tools were found to be fundamentally suitable for machining plastics, while the glass tools failed when machining aluminum.

- The cause of the total failure of the glass tools is to be found in stresses. When the tools are clamped in the holder, they are clamped in place by a claw and thus build up high levels of tension. Any residual stresses that already exist inside the tools are superimposed by the clamping stresses. The additional load stresses that occur during machining are added so that the sum of all stresses can exceed the tensile strength of the material. Tool failure occurs. This is more likely to occur with the two glasses than with the glass ceramic, since the glasses have a significantly higher hardness. As a result, stronger tensions build up when the tools are clamped than with the soft material, which reacts to the clamping load through plastic deformation.

- The glass ceramic tools were found to be suitable also for machining aluminum. A recommendation for the use of glass and glass ceramic inserts cannot yet be given.

- Further research will be required for this. So it is important to first find out the most suitable from the large selection of available glass and glass ceramic materials. Furthermore, the suitable control variables for grinding of the individual types of material must be found, and the micro-geometry (chamfers, cutting edge rounding, etc.) must be adapted to the subsequent task of the tools. Ultimately, a possible PVD coating of the tools should also be considered. All in all, there are interesting options for the gradual substitution of existing cutting materials.

\section{SN Applied Sciences}

Authors' contributions BB: Came up with the idea for the research. He planned the concept for the implementation, had all the analyzes carried out, took over the evaluations and wrote the manuscript; DMC performed all grinding tests and manufactured all indexable inserts. He checked the information in the manuscript; NV carried out all cutting tests with the new tools and provided all related results and information. He also checked the contents of the manuscript.

Funding Open Access funding enabled and organized by Projekt DEAL.

Data availability and material All data and additional glass ceramic tools are available at the institute.

\section{Declarations}

Conflict of interest The authors declare that there is no conflict of interests.

Open Access This article is licensed under a Creative Commons Attribution 4.0 International License, which permits use, sharing, adaptation, distribution and reproduction in any medium or format, as long as you give appropriate credit to the original author(s) and the source, provide a link to the Creative Commons licence, and indicate if changes were made. The images or other third party material in this article are included in the article's Creative Commons licence, unless indicated otherwise in a credit line to the material. If material is not included in the article's Creative Commons licence and your intended use is not permitted by statutory regulation or exceeds the permitted use, you will need to obtain permission directly from the copyright holder. To view a copy of this licence, visit http://creativecommons. org/licenses/by/4.0/. 


\section{References}

1. Hou ZB, Komandouri R (2003) On the mechanics of the grinding process-part I. Stochastic nature of the grinding process. Int J Mach Tools Manuf 43:1579-1593. https://doi.org/10.1016/ S0890-6955(03)00186-X

2. Denkena B, Köhler J, Kästner J (2012) Chip formation in grinding: an experimental study. Prod Eng Res Devel 6:107-115. https:// doi.org/10.1007/s11740-011-0360-8

3. Denkena B, Busemann S, Gottwik L, Grove T, Wippermann A (2017) Material removal mechanisms in grinding of mixed oxide ceramics. Procedia CIRP 65:70-77. https://doi.org/10.1016/j.procir.2017.04.011

4. Denkena B, Breidenstein B, Strug M (2019) Intelligente Werkzeugzustandsüberwachung beim Schleifen. Journal für Oberflächentechnik JOT 59(11):54-57. https://doi.org/10.1007/ s35144-019-0376-y

5. Rowe BW (2017) Temperatures in grinding - a review. J Manuf Sci Eng 139:1-6. https://doi.org/10.1115/1.4036638

6. Brinksmeier E, Aurich JC, Govekar E, Heinzel C, Hoffmeister HW, Klocke F, Peters J, Rentsch R, Stephenson DJ, Uhlmann E, Weinert $\mathrm{K}$, Wittmann M (2006) Advances in modelling and simulation of grinding processes. Annals CIRP 55:667-696. https://doi.org/10. 1016/j.cirp.2006.10.003

7. Brient A, Brissot M, Rouxel T, Sangleboeuf JC (2011) Influence of grinding parameters on glass workpieces surface finish using response surface methodology. J Manuf Sci Eng 133(4):044501. https://doi.org/10.1115/1.4004317

8. Bukieda P, Lohr K, Meiberg J, Weller B (2020) Study on the optical quality and strength of glass edges after the grinding and polishing process. Glass Struct Eng 5:411-428. https://doi.org/ 10.1007/s40940-020-00121-x

9. Wolters P, Picker T, Breidenstein B, Krödel A, Denkena B (2021) Application of naturalrocks in cutting aluminum. In: Behrens BA, Brosius A, Drossel WG, Hintze W, Ihlenfeldt S, Nyhuis P (eds) Production at the leading edge of technology. Springer, Cham

10. Garai M, Murthy TSRCh, Karmakar B (2018) Microstructural characterization and wear properties of silver and gold nanoparticle doped K-Mg-Al-Si-O-F glass-ceramics. Ceram Int 44(18):2230822317. https://doi.org/10.1016/j.ceramint.2018.08.356

11. Garai M, Reka AA, Karmakar B (2021) Molla AR (2021) Microstructure-mechanical properties of $\mathrm{Ag}^{0} / \mathrm{Au}^{0}$ doped K-Mg-Al-Si-O-F glass-ceramics. RSC Adv 11:11415-11424. https://doi.org/10. 1039/d0ra10519h

12. Ovsik M, Manas D, Manas M, Stanek M, Kyas K, Bednarik M, Mizera A (2012) Effect of beta irradiation on the microhardness of HDPE. In: Proc. 16th WSEAS International conference on circuits and systems, Kos Island, Greece 285-288.

13. Yan Y, Jiang C, Huo Y, Li C (2020) Preparation and tribological behaviours of lubrication-enhanced PEEK composites. Appl Sci 10:7536. https://doi.org/10.3390/app10217536

14. Zagar S, Grum J (2011) Surface integrity after mechanical hardening of various aluminium alloys. J Mech Eng 57:334-344. https://doi.org/10.5545/sv-jme.2010.092

15. Bifano TG, Dow TA, Scattergood RO (1991) Ductile-regime grinding: A new technology for machining brittle materials. J Eng Ind 113(2):184-189. https://doi.org/10.1115/1.2899676

16. Rahman M, Ramakrishna S, Thoo HC (1999) Machinability study of carbon/PEEK composites. Mach Sci Technol 3(1):49-59. https://doi.org/10.1080/10940349908945682

17. Davim JP, Reis P, Lapa V, Antonio CC (2003) Machinability study on polyetherether-ketone (PEEK) unreinforced and reinforced (GF30) for applications in structured components. Compos Struct 62:67-73. https://doi.org/10.1016/S0263-8223(03) 00085-0

18. Mata F, Gaitonde VN, Karnik SR, Davim JP (2009) Influence of cutting conditions on machinability aspects of PEEK, PEEK CF 30 and PEEK GF 30 composites using PCD tools. J Mater Process Technol 209:1980-1987. https://doi.org/10.1016/j.jmatprotec. 2008.04.060

Publisher's Note Springer Nature remains neutral with regard to jurisdictional claims in published maps and institutional affiliations. 